San Jose State University

SJSU ScholarWorks

Master's Theses

Master's Theses and Graduate Research

1996

\title{
Home health nurses' knowledge of diabetes and diabetic patient outcomes : a replication study
}

Valerie D. Isaacson

San Jose State University

Follow this and additional works at: https://scholarworks.sjsu.edu/etd_theses

\section{Recommended Citation}

Isaacson, Valerie D., "Home health nurses' knowledge of diabetes and diabetic patient outcomes : a replication study" (1996). Master's Theses. 1230.

DOI: https://doi.org/10.31979/etd.pgna-v6xx

https://scholarworks.sjsu.edu/etd_theses/1230

This Thesis is brought to you for free and open access by the Master's Theses and Graduate Research at SJSU ScholarWorks. It has been accepted for inclusion in Master's Theses by an authorized administrator of SJSU ScholarWorks. For more information, please contact scholarworks@sjsu.edu. 


\section{INFORMATION TO USERS}

This manuscript has been reproduced from the microfilm master. UMI films the text directly from the original or copy submitted. Thus, some thesis and dissertation copies are in typewriter face, while others may be from any type of computer printer.

The quality of this reproduction is dependent upon the quality of the copy submitted. Broken or indistinct print, colored or poor quality illustrations and photographs, print bleedthrough, substandard margins, and improper alignment can adversely affect reproduction.

In the unlikely event that the author did not send UMI a complete manuscript and there are missing pages, these will be noted. Also, if unauthorized copyright material had to be removed, a note will indicate the deletion.

Oversize materials (e.g., maps, drawings, charts) are reproduced by sectioning the original, beginning at the upper left-hand corner and continuing from left to right in equal sections with small overlaps. Each original is also photographed in one exposure and is included in reduced form at the back of the book.

Photographs included in the original manuscript have been reproduced xerographically in this copy. Higher quality 6" $\times$ 9" black and white photographic prints are available for any photographs or illustrations appearing in this copy for an additional charge. Contact UMI directly to order.

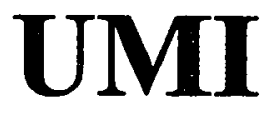

A Bell \& Howell Information Company 300 North Zeeb Road, Ann Arbor MI 48106-1346 USA

$313 / 761-4700 \quad 800 / 521-0600$ 



\title{
HOME HEALTH NURSES' KNOWLEDGE OF DIABETES \\ AND \\ DIABETIC PATIENT OUTCOMES: A REPLICATION STUDY
}

\author{
A Thesis \\ Presented to \\ The Faculty of the School of Nursing \\ San Jose State University \\ In Partial Fulfillment \\ of the Requirements for the Degrce \\ Master of Sciencc
}

by

Valerie D. Isaacson

May 1996 
UMI Number: 1379345

\section{Copyright 1996 by \\ Isaacson, Valerie D.}

All rights reserved.

UMI Microform 1379345

Copyright 1996, by UMI Company. All rights reserved.

This microform edition is protected against unauthorized copying under Title 17, United States Code.

\section{UMI \\ 300 North Zeeb Road \\ Ann Arbor, MI 48103}




\section{C01996}

Valerie D. Isaacson

ALL RIGHTS RESERVED 
A.PPROVED FOR THE SCHOOL OF NURSING

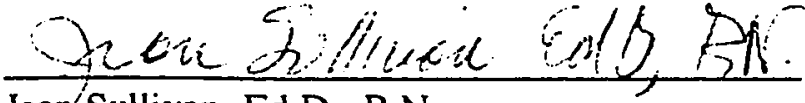

Jean'Sullivan, Ed.D., R.N.

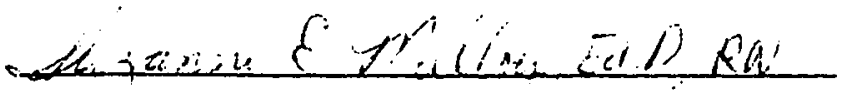

Suzanne E. Malloy, Ed.D., R.N.

7

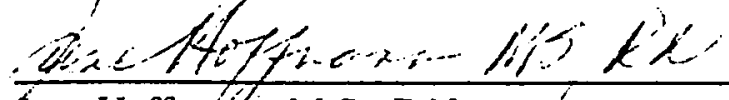

Jane Hoffmán, M.S., R.N.

APPROVED FOR THE UNIVERSITY

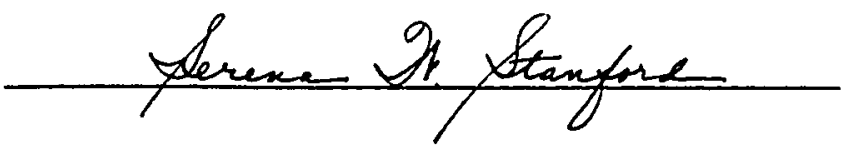




\section{ABSTRACT \\ HOME HEALTH NURSES' KNOWLEDGE OF DIABETES \\ AND DIABETIC PATIENT OUTCOMES: A REPLICATION STUDY \\ by Valerie $D$. Isaacson}

The purpose of this study, using a nonexperimental descriptive/exploratory survey research design, was to determine if the findings of the Adams and Cook (1994) study could be replicated utilizing the same data collection tools and methodology in two similar urban Medicare certified home health agencies in the San Francisco Bay area. Adams and Cook found that nurses scored higher on the Diabetes: Basic Knowledge Test and had higher scores relating to nursing care standards for diabctic patients on the Nursing Care Intervention Tool at the agency that employed a diabetic nursc cducator compared to the agency that did not employ a diabetes nurse educator. In contrast, the results of this study found that there was no statistical significant difference between the two agencies using these two instruments. Questions for future research were gencratcd from the data obtained in this study. 


\section{ACKNOWLEDGEMENTS}

I would like to extend my sincere appreciation to my daughters Erica, who was my research assistant, and Brina, who helped maintain our household. I would also like to thank my husband Jim, without whose computer expertise I would never have completed graduate school.

In memory of Dorothy Minchin, my mother, who faithfully followed her diabetic regimen and encouraged others with diabetes. 


\section{TABLE OF CONTENTS}

Page

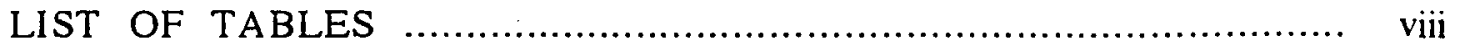

\section{Chapter}

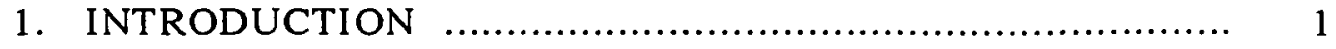

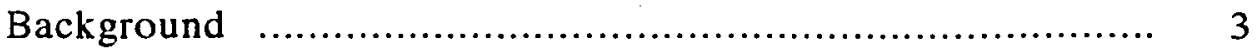

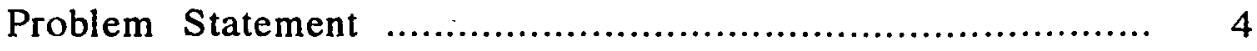

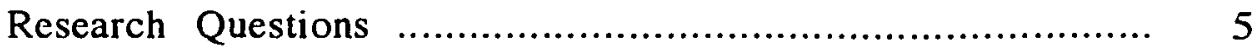

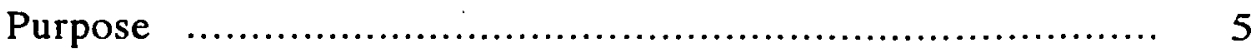

Definition of Terms (............................................... 6

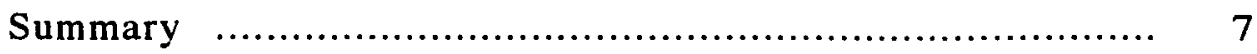

2. CONCEPTUAL FRAMEWORK AND REVIEW OF

RELATED LITERATURE ................................. 8

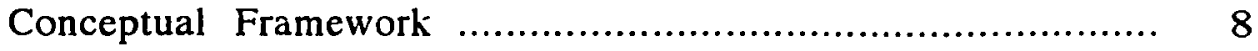

Literature Review ................................................ 9

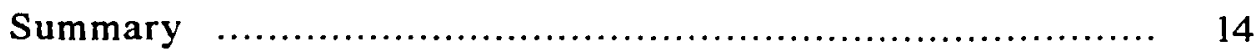

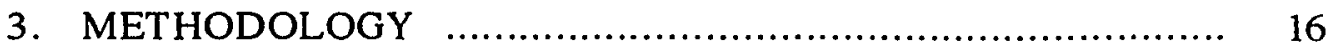

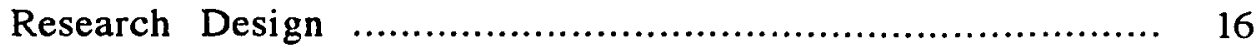

Subject / Setting .................................................. 16

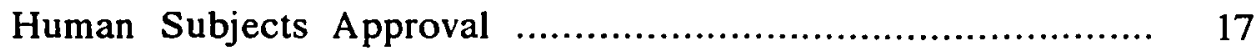

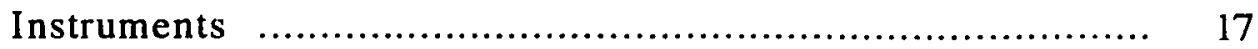

Data Collection ................................................. 19

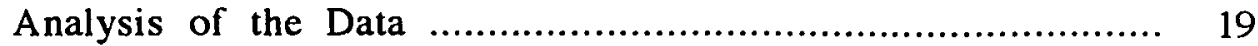

4. ANALYSIS AND INTERPRETATION OF DATA ..................... 20

5. CONCLUSIONS AND RECOMMENDATIONS ........................ 25 


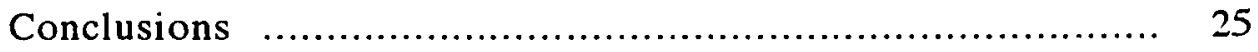

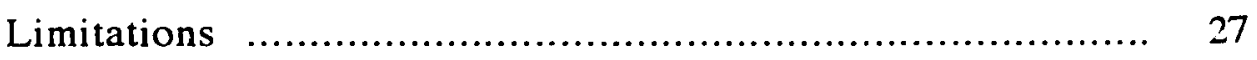

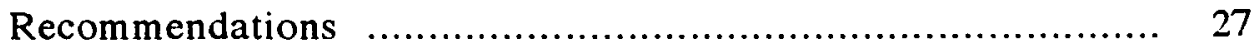

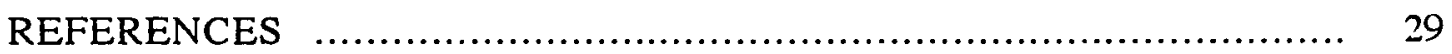

APPENDICES

A. Diabetes: Basic Knowledge Test (DBKT) ......................... 33

B. Nurse Information Questionnaire (NIQ) ............................ 45

C. Nursing Care Information Tool (NCIT) .......................... 47

D. Patient Characteristics Questionnaire (PIQ) ........................ 52

E. Human Subjects Approval ..................................... 54 


\section{LIST OFTABLES}

Tables Page

1. Diabetes: Basic Knowledge Test Scores for the Samples.................... 20

2. Nursing Care Intervention. Tool Scores for the Samples.................... 21

3. Demographic Data from the Nurse Information Questionnaire .............. 22

4. Comparison of Admission and Discharge Blood Glucose Readings ......... 23 


\section{Chapter 1}

\section{INTRODUCTION}

Diabetes mellitus is a chronic illness that affects approximately 14 million people in the United States (U.S.), according to the National Institute of Diabetes and Digestive and Kidney Diseases (1994). They also report that of this number, approximately 6 to 7 million diabetics are undiagnosed; many of them are elderly with non-insulin-dependent diabetes (NIDDM), despite more than 650,000 new cases diagnosed annually. Approximately 90 to 95\% of diabetics have NIDDM, with over half of these individuals being over age 55.

According to the American Diabetes Association (ADA) (1993), diabetes is the seventh leading cause of death and is the cause of $1.8 \%$ of the total U.S. mortality rate (approximately 200,000 lives per year). This mortality rate is partially due to the long-term complications related to diabetes (e.g., retinopathy, nephropathy, and neuropathy).

Diabetics over the age of 65 of ten have more than one complication related to diabetes. They are at increased risk for cardiovascular diseases associated with diabetes resulting in hypertension, stroke, and amputations.

The National Institute of Diabetes and Digestive and Kidney Diseases (1994) also reported that in 1992 diabetes was responsible for $\$ 95$ billion for direct medical costs and $\$ 47$ billion in indirect costs such as disability, work loss, and premature mortality. Rubin, Altman, and Mendelson (1994) concluded that the total health care expenditures in 1992 for a person with diabetes were three times more than for a person without diabetes and represented $11.9 \%$ of the total U.S. health care expenditures. This did not include any indirect costs or costs associated with nursing home care or nonprescription drugs. With the proposed cutbacks in Medicare coverage by the federal government, it is increasingly important that funds continue to be authorized for diabetes education by nurses. Money would be better spent on education to assist people with diabetes to improve their control and decrease the incidence of the complications of diabetes.

According to Minaker (1990) there will be double the number of people over the age 
of 65 by the year 2030 and the number of people over the age of 85 will triple by the year 2020. Of these groups, 40 to $50 \%$ of them will have diabetes or impaired glucose tolerance. This has important implications for diabetes screening programs, both for those elderly who are in the community and for those in residential care homes and skilled nursing facilities.

An important event for people with diabetes and heal th professionals working with diabetics was the publication of the Diabetes Control and Complication Trial (DCCT) results. The preliminary results were initially published by the Diabetes Control and Complications Research Group in 1987 and the final results were reported in 1993. This study of Type I diabetics, also known as insulin dependent diabetes mellitus (IDDM), showed that an intensive therapy regimen, with the goal to maintain optimal blood glucose control, delayed the incidence and slowed the progression of the three major complications of diabetes: retinopathy, nephropathy, and neuropathy. In this study, the incidence of retinopathy was decreased by $76 \%$, nephropathy by $35 \%$, and neuropathy by $60 \%$. This study also established the glycosylated hemoglobin (HbA lc) blood test and the serum glucose test as the measurements that should be used to determine an individual's control of their diabetes. Jornsay and Cypress (1994), Muchmore (1994), and the ADA (1995 a) reported at the second Consensus Development Conference on Self-Monitoring of Blood Glucose held in September, 1993. This established for the first time that maintaining a diabetes regimen for optimal blood glucose control also could decrease the risk of complications in NIDDM.

Recent technological advances have made it much simpler for people with diabetes to monitor their blood glucose levels at home using small hand held meters requiring only a drop of blood from a finger-stick. According to the ADA (1995 a,b,c) position statements, self-monitoring of blood glucose testing (SMBG) is a far more accurate method than urine glucose tests both for IDDM and NIDDM patients. Urine glucose testing was the only method for home glucose monitoring for many years. This resulted in many diabetics being 
managed by their physicians with what is now known to have been high blood glucose levels that, in turn, caused the devastating complications of diabetes. There should be a decrease in the incidence and severity of the complications of diabetes if people with diabetes can be educated and motivated to use meters to monitor their blood glucose levels, and use the information to make changes in how they manage their diabetes.

The position of the diabetes nurse educator (DNE) working at a home health agency (HHA) could play a major role in decreasing the total health care expenditures for people with diabetes. Rubin et al. (1994) found that $63 \%$ of the total health care expenditures for diabetics were for inpatient care and $4 \%$ were expended for home health care. The cost of home care is far less than that of hospitalization. If, for example, the DNE was to teach all diabetics how to recognize and treat the signs and symptoms of hypoglycemia and hyperglycemia, the potential decreased rate of emergency room visits and subsequent hospitalizations would more than pay for his or her salary.

\section{Background}

Adams and Cook (1994) and Strock, Jacobson, Reader, and Hollander (1988) stated that diabetes is a frequent primary or secondary diagnosis for patients served by HHA's. In the past, people with diabetes stayed in the hospital until their condition had stabilized for at least a day or two and they had an opportunity to meet with the DNE to learn about any new aspects of their diabetes regimen. Funnell (1990) discussed the role of the diabetes educator as an important member of the hospital health care team providing instruction to diabetics and their families. In the current cost containment environment in the acute care hospital, the shortened length of stay and decreased staffing do not allow time for review or teaching of new information for diabetic patients by either the hospital staff nurses or by the DNE, if available, before discharge.

With the shift of the health insurance industry to managed care, the family practice physician rather than the endocrinologist will be the one providing most of the care to people with diabetes. The family practitoner usually allocates 15 minutes for an office visit and that may not allow adequate time for instruction or review of the patient's diabetes 
management. The DNE could become a partner with the physician to provide diabetes management for his patients at his office. The DNE could become an employee or consultant to the acute care hospital in-patient or out-patient department, or to a home health agency. This would provide an opportunity for the DNE to play a major educational role in facilitating active participation and self-care to people with diabetes. These diabetics of ten require a complex regimen to maintain optimal metabolic control and decrease the incidence of diabetic complications.

Beginning in 1986, a health professional could become a certified diabetes educator (CDE) by meeting the requirements and taking a national exam sponsored by the American Association of Diabetes Educators (AADE). The National Certification Board for Diabetes Educators (1992), established by the AADE, developed and implemented this certification process. A masters degree prepared clinical nurse specialist (CNS), with a focus on diabetes, is eligible to become a CDE. This would add to that individual's credibility with the staff he or she works with and add his or her diabetes expertise in the roles of consultant, educator, and researcher. The main focus of his or her practice would be to improve the diabetic patient's outcomes. Another focus would be to improve the staff's level of knowledge about diabetes.

\section{Problem Statement}

The problem in home health care today is that in many agencies, there is not a diabetes nurse educator to act as a resource person and clinical expert for the staff. Diabetes is a complex medical condition that is of ten managed by an equally complex regimen. Nurses and other home health care staff are usually the ones that assist the patient and their caregivers to learn how to integrate the diabetic regimen into their daily lives. The publication of the DCCT results and the availability of easy to use meters for blood glucose testing at home has helped people with diabetes to be in control of their illness. It was expected that this study would validate Adams and Cook's (1994) findings that the nurses at the home heal th agency (HHA) with the diabetes nurse educator (DNE) had higher 
scores on the Diabetes: Basic Knowledge Test (DBKT) ( Appendix A) and provided a higher level of care to their patients with diabetes. This instrument tested nurses' knowledge about diabetes and the care of patients with diabetes. It was hoped that, because of this study, more HHA's would recognize the value of employing nurses in the role of DNE's to produce optimal patient outcomes. This study focuses on the importance of having nurses working in home health care who are experts in the nursing management of diabetes in the home care setting.

\section{Research Questions}

The following two research questions were asked:

1. Is there a difference in knowledge of diabetes mellitus between staff nurses in a home care agency that employs a nurse certified diabetic educator (CDE) compared to staff nurses in a home care agency that does not employ a nurse CDE?

2. Do staff nurses in a home care agency with a nurse CDE give a different level of nursing care to patients with diabetes compared to staff nurses in a home care agency without a nurse CDE?

\section{Purpose}

The purpose of this study was to determine if the findings of the Adams and Cook (1994) study could be replicated using the same data collection tools and methodology in two similar urban Medicare certified home health agencies in the San Francisco Bay area. One HHA employed a CDE and used a team approach to diabetic patient care and the other agency did not employ a CDE, nor was care provided care by a diabetes nurse team.

Adams and Cook (1994) used two Medicare-certified home health agencies in Washington state serving urban and rural populations. One agency employed a DNE and one did not, although the study did not state whether the DNE was a CDE. This model was used as a basis for replicating similar approaches in two home health agencies in the San Francisco Bay area.

This study was conducted to find if there was any difference in the specific nurse's 
knowledge about diabetes and if there was any difference in patient outcomes between the two agencies.

\section{Definition of Terms}

The following definitions were used in this study:

1. Diabetes mellitus is "a heterogeneous group of disorders of intermediary metabolism characterized by glucose intolerance, with hyperglycemia present at the time of diagnosis" (Peragallo-Dittko, Godley, \& Meyer, 1993, p. 111).

2. A diabetes educator is "a health care professional who has mastered the core of knowledge and skill in the biological and social sciences, communication and counselling, and education, and who has experience in the care of patients with diabetes" (PeragalloDittko, et al. 1993, p. viii).

3. A diabetes nurse educator (DNE) is a diabetes educator who is a registered nurse.

4. A certified diabetes educator (CDE) is a health care professional who has met the requirements of the National Certification Board for Diabetes Educators. A registered nurse, registered dietitian, registered pharmacist, physician assistant, medical technologist, or a health care professionai with a master's degree are eligible to take the certification exam. The first certification exam was offered in 1986.

5. Glycosolated hemoglobin (HbAlc) level is the measurement of glucose control over a 3 to 4-month period and reflects the glucose in the plasma attached to the hemoglobin component of the red blood cell. The normal value is $4 \%$ to $7 \%$ depending on the laboratory used (Peragallo-Dittko, et al. 1993).

6. $\underline{\text { Strock }} \underline{\text { Level of }}$ Care was used in the Nursing Care Intervention Tool and developed by Strock, Jacobson, Reader, and Hollander (1988) that categorizes patients with diabetes into three levels of care concerning their diabetes. Level I is for patients that are:

...newly diagnosed or diagnosed as having diabetes for less than six months. ... Level II ... patients have had diabetes for more than 6 months and demonstrate an inability to integrate their medical management plan into 
their daily lives. .. . Level III patients have had a recent acute or chronic medical problem that impedes self management. (p. 53)

\section{Summary}

Diabetes is a chronic illness that will affect an increasing number of people as the population ages. Diabetes will therefore have a major impact on the morbidity and mortality of the population and a major impact on the health care economy.

The results of the DCCT study for Type I diabetes have shown that an improvement in blood glucose control significantly decreases the incidence of the major complications of diabetes. These same results also can be obtained for Type II diabetes. The technological improvements in the meters, their reasonable cost, or coverage by insurance companies have given diabetics a way to monitor their blood glucose. This has resulted in a need for education to diabetics and their families regarding what they can do to manage their diabetes. A major role can be played by a DNE in educating people with diabetes about how they can work in partnership with their health care team rather than takc a passive role. Extensive literature is available to support this role for nurses. 
Chapter 2

\section{CONCEPTUALFRAMEWORK AND REVIEW OF RELATED LITERATURE Conceptual Framework}

The conceptual framework for this study is the Linkage Model that was developed initially by Havelock (1971) as a sociological theory to explain and improve the dissemination and utilization of new knowledge in the education setting. Havelock described the user of this model to be a problem solver who is professionally related to outside resources and who interacts with these resources to help in problem resolution. The model also involves a two-way communication between the users of the knowledge and the resources used to solve problems.

Girouard (1983) discussed how she applied Havelock's Linkage Theory of planned change to the role of the clinical nurse specialist (CNS) using the Linkage Model. The main functions of the CNS role, according to Girouard, is that of a change agent. In the implementation of the change process using this model, the staff nurse is the problem solver and the CNS is the change agent. The CNS acts as the link between the resources and the nursing staff. In this role the CNS helps the staff with the diagnosis of the problem. This is done by guiding the discussion regarding different possibilities, using other sources for information, adding her knowledge to the discussion, offering alternatives and possible solutions, and acting as a link to other resources. Girourard found that the CNS is in an ideal position to provide the link between theory and practice.

Davis (1990) also used the Linkage Model to discuss how the clinical nurse specialist diabetes nurse educator role could act as a link between the staff nurses and the patients with diabetes in the hospital setting. Their role was to increase the knowledge of staff nurses about diabetes and to increase patients' knowledge of diabetes and their level of self-care. The DNE can do this by linking multiple diabetes resources with the users. The users could be the patient, family, caregivers, physicians, and/or nurses. The result is that people with diabetes are participants in quality-assured and cost-efficient care that is very 
important in the current cost containment environment, whether it be in home care or the acute care hospital setting.

\section{Literature Review}

The review of related literature is divided into two areas: (a) studies related to the role of improved metabolic control of diabetes to decrease the incidence of the complications of diabetes, and (b) studies related to the role of the DNE and improved diabetic patient outcomes.

Role of improved metabolic control to a decreased incidence of diabetes complications

The DCCT study $(1987,1993)$, described earlier, is used as a comparison for similar studies done in other parts of the world. Reichard, Britz, Carlson, Cars, Lindblad, Nilsson, and Rosenqvist (1990) did a similar 3 year study of insulin dependent diabetes mellitus (IDDM) in Sweden, known as the Stockholm Diabetes Intervention Study (SDIS). Their results showed that with the group that used intensive insulin therapy to bring blood glucose levels close to the normal range compared to conventional insulin therapy, there was a statistically significant decrease in the HbA lc levels. There was no deterioration in nerve conduction or kidney function. Both the intensive insulin therapy group and the regular insulin therapy group had an increased incidence of retinopathy. As in the DCCT study, there was a higher incidence of serious hypoglycemic reactions due to the goal to maintain blood glucose at near normal levels. Hypoglycemia, or low blood sugar, causes unpleasant symptoms such as increased heart rate, palpitations, sweating, hunger, irrational behavior, fatigue, drowsiness, and can progress to seizures and coma if not corrected. This study concluded that improved control of blood glucose levels did slow the progression of microvascular complications.

Reichard, Toomingas, and Rosenqvist (1994) used the same poorly controlled and unmotivated subjects who participated in the SDIS. The intensive conventional treatment (ICT) and the regular treatment (RT) groups used in this study were again used to determine if this made a difference regarding changes in the participants' ideas and attitudes about their diabetes. The ICT included structured individual education, home self- 
monitoring of blood glucose (SMBG) with individual blood glucose goals, bi-weekly telephone contacts initially, and bi-monthly office visits. The RT group met with the physician every fourth month and received SMBG instructions and monitoring of their blood glucose. The goal was to change the focus of the ICT group from thinking that diabetes is a disease treated with insulin to thinking of diabetes as a disease with an insulin deficiency that could be corrected with adequate insulin administration. The results showed that after 5 years the ICT group displayed a significant decrease in their HbA lc levels and that they were lower than the RT group. The ICT group also showed that their feelings of well being and their perceived ability to control their diabetes was greater. The most important factor for the ICT group was the use of SMBG to achieve better blood glucose levels. The ICT group also had fewer serious complications of diabetes and did not require any increased physician time. The ICT group felt that their improved knowledge about their diabetes and their ability to manage unstable blood glucose levels improved their feelings of well being. This study showed that the follow-up visits werc made to a physician/tutor but did not identify the qualifications of this person.

Morley and Perry (1991) found that if the blood glucosc lcrels of people with NIDDM over the age of 65 are kept below $200 \mathrm{mg} / \mathrm{dl}$ that the development of diabetic complications will be slowed or decreased. This is significant becausc 5()$\%$ of the people with NIDDM are over the age of 65. Morley and Perry also reportcd that slder people with diabetes were found to have a higher incidence of depression that could lcad to a decrease in compliance to the diabetic regimen. This may occur as an cxtrancous variable in this study because of the primarily elderly diabetic patient population who of ten have more than one chronic medical condition.

Lebovitz and Vinik (1991) reported on the results of several studies and concluded that there was not any difference between NIDDM and IDDM in the development of the main complications of diabetes (retinopathy, neuropathy, and nephropathy). Some of the studies found that there was a correlation between duration of diabetes, poor glycemic 
control, and the development of these complications.

Etzwiler (1994) and Franz, Callahan, and Castle (1994) discussed the recommendation of the DCCT that diabetes care be delivered by teams and the importance of including the patient as a team member. The other team members would include a doctor, nurse educator, dietitian; and may include a behaviorist, exercise physiologist, and pharmacist. The primary focus of the team is patient education. The diabetic team must advocate for the patient with insurance plans that deny reimbursement for patient education and SMBG supplies. The result of helping the patient to achieve the optimal control of their diabetes was a lowering of the HbA lc level and decreasing the incidence of costly complications.

Studies related to the role of the DNE and improved diabetic patient outcomes

To maintain metabolic control, the person with diabetes and of ten their families, must actively participate in the management of this chronic condition with the members of the diabetic team. With the increased emphasis on cost-effective care, the physician's time spent with the patient is limited and does not allow time for education regarding diabetic management. Dudley (1980) discussed the beginnings of the role of the diabetes nurse educator (DNE) with her experience working in collaboration with a physician. The need for patient education was recognized and physicians agreed that nurses were better able to take on this role than themselves. Dudley (1980) stated that the DNE role was to assess the patient's knowledge and needs, provide individualized education either one-to-one or to groups, and prepare the patient for any future problems that may occur.

Davis (1990) discussed the role of the DNE in improving patient education by acting as a change agent and a consultant to the staff nurses in the hospital setting. The DNE worked collaboratively with both the physician and the staff nurses to deliver quality care and education regarding diabetes self-care in a cost effective manner. The staff nurse is the one spending the most time with the patient but the diabetes nurse educator (DNE) is the one that acts as a role model for expert clinical practice with patients and professionals. 
Cyprus, Wylie-Rosett, Engel, and Stager (1992) discussed the role of the certified diabetic educator (CDE) and how it was developed to help people with diabetes and their physicians to promote adherence to the diabetic treatment regimen. Health-care professionals (usually nurses, but also dietitians, physicians, or social workers,) may qualify to take the examination developed by the National Certification Board of Diabetes Educators. The CDE, as discussed by Funnell (1990), works as a member of the healthcare team to provide all aspects of diabetic education to patients and their families. Funnell found that not all health professionals who call themselves diabetes educators are knowledgeable about diabetes and may have lacked training in educational theory and practice. Those educators who are certified need to advocate for adherence to the certification requirements for all who teach diabetic management.

The Adams and Cook (1994) study, replicated by this study, compared nurses' knowledge of diabetes and nursing care interventions for patients with diabetes in two home care agencies. There were 45 nurses at the one agency that had a DNE and 17 nurses in the agency that did not employ a diabetes educator. They completed the Diabetes: Basic Knowledge Test (DBKT) questionnaire (Appendix A) and the author-developed Nurse Information Questionnaire (NIQ) (Appendix B). The results showed that the nurses in the agency with the DNE were significantly more knowledgeable about diabetes. A chart audit of IDDM patient records was done at the two agencies using the Nursing Care Intervention Tool (NCIT) (Appendix C) and the Patient Characteristics Questionnaire (Appendix D). Both the NCIT and PCQ tools were developed by Adams and Cook. This chart audit showed that the agency with the DNE provided a significantly higher standard of diabetic patient care than the nurses in the agency without a DNE. These results were attributed to the use of standard care plans, teaching tools, and orientation modules developed for the care of diabetic patients.

The treatment regimen for diabetes has become increasingly complex and expensive, with new technological developments concerning blood glucose testing, new medications and insulin protocols. This can be especially challenging for those diabetics 
over the age of 65 who may already have visual impairments, decreased manual dexterity, and other medical problems. Diabetic education is an important role for the nurse as a CDE and'or a diabetic CNS as a member of a multidisciplinary diabetes team. Increased knowledge by diabetics and those who care for them may make a major difference in meeting the goals of optimal control of each patients' diabetes. This may also result in the prevention, delay of onset, or decreased severity of the complications of diabetes.

The Diabetes Knowledge Test (DKT) originally was developed by Etzwiler (1967) and was updated by Scheiderich, Freibaum, and Peterson (1983) with good content reliability (coefficient alpha reliability of .62). The Scheiderich et al. (1983) study measured nurses' knowledge of diabetes in three hospitals using the DKT. They found that nurses at the hospital using a separate diabetes teaching service with clinical specialists to teach diabetic patients scored lower on the DKT. The overall results showed that the mean score was only 25.3 or $74 \%$. The recommendation was made for regular inservices on diabetes for all nurses and for the diabetes educators to share their expertise with the staff nurses.

Drass, Muir-Nash, Boykin, Turek, and Baker (1989) further updated and expanded the DKT by Scheiderich et al. (1983) and renamed the questionnaire the Diabetes: Basic Knowledge Test (DBKT). The Drass et al. (1989) study administered the DBKT to nurses in a large research-teaching hospital (reliability coefficient of .79) to assess the staff nurses level of basic knowledge about diabetes. There was no designated diabetes educator at the hospital. The mean correct score on the 45 question DBKT was 28.6 that again showed a need for periodic diabetes education classes for all nurses involved with teaching diabetic patients. The main reason attributed to the poor staff score on the Diabetes: Basic Knowledge Test (DBKT) was that they were not keeping up to date with the new technological developments and research findings regarding diabetes care. The nurses' lack of current diabetes knowledge also may be an important factor in his or her patient's lack of compliance with the diabetes regimen.

Gossain, Bowman, and Rovner (1993) also used the 45 question DBKT in a study 
of the actual and self-perceived knowledge of diabetes among staff nurses. This was a replication of the study done by Drass et al. (1989) using 127 staff nurses at three hospitals. Each hospital, in the Gossain et al. (1993) study, had a certified diabetes educator (CDE) compared to Drass's et al. study that did not have a diabetes nurse educator (DNE). A Chronbach's alpha was used for internal consistency with a reliability coefficient of .79 obtained from the study by Drass et al. The mean score on the DBKT for the Gossain et al. study was 31 compared to 28.6 for the Drass et al. study. This difference could have been due to the presence of a CDE at each hospital in the Gossain et al. study. Both studies found a significant lack of basic diabetes knowledge that is an important concern with the increasing number of diabetic patients.

Another study done by Jayne and Rankin (1993) also used the DBKT and a demographic tool to survey 99 staff nurses at an acute care hospital that employed a diabetes clinical nurse specialist. In this study the researchers investigated the nurses' lack of updated knowledge of diabetes. This lack of knowledge was reflected in the mean knowledge score of $73 \%$. This score was better than either the Drass et al. (1989) or the Gossain et al. (1993) study. The study by Jayne and Rankin (1993) also showed that nurses who cared for a higher number of diabetic patients and who felt confident in their ability to provide care to diabetic patients scored higher on the DBKT. The study also gave suggestions on how the diabetes clinical nurse specialist could carry out a staff diabetes education program.

\section{Summary}

This chapter introduced the conceptual framework used in this study to describe how Havelock's Linkage Model could be used in the development of the role of the clinical nurse specialist (CNS) as a diabetes nurse educator (DNE). A summary of the current published literature has been presented regarding the studies that have been done to show the importance of maintaining blood glucose levels within or as close to the normal range as possible, as recommended by the results of the Diabetes Control and Complications Trial (DCCT) to prevent the complications of diabetes. The literature review also discussed the 
role of the DNE in providing the optimal level of care to people with diabetes and the role of educator both to the patients and to the staff. Other studies, completed in hospital settings, that used the Diabetes: Basic Knowledge Test (DBKT) were reviewed. This study used the DBKT in two urban home health agencies, one with a diabetes nurse educator (DNE) and one without a DNE to determine if the DNE affected the scores of the nurses working at that agency. 
Chapter 3

\section{METHODOLOGY}

Research Design

This study used a nonexperimental descriptive/exploratory survey research design. The independent variable was the site at which the data was collected and the dependent variable was the score on the Diabetes: Basic Knowledge Test (DBKT) and the Nursing Care Intervention Tool (NCIT). This type of research design was selected to replicate the methodology used in the Adams and Cook (1994) study.

\section{Subject / Setting}

The sample population for this study was two Medicare-certified home health agency's (HHA's) in the San Francisco Bay area chosen for the convenience of the researcher. The criterion used for choosing the agencies was that one employed a certified diabetic educator (CDE) in a diabetes nurse educator (DNE) role and the other agency did not. The Adams and Cook study used a similar population with the differences that their sample populations were smaller and were from one urban and one rural home health agency.

This study sample included 104 registered nurses at the agency with the DNE and 68 registered nurses at the agency without a DNE who provided intermittent visits to patients in their homes. Both agencies served an urban population, and each had the same state and federal standards for nursing care. The two agencies were similar to one another in most other respects. The nurses were invited to participate in the study during presentations, either at a monthly nurse meeting or at a weekly team meeting; to explain what would be involved if they participated in the study. The study instruments, with a cover sheet attached explaining the study, were distributed to the nurses' mail boxes at each agency. They were requested to return the forms to the Inservice Educator at their respective agency. All information collected was kept confidential, and participation by the nurses was voluntary. In an effort to generate an increased response rate, three voice mail 
reminders, one week apart, were given to the nurses at the agency with the DNE. Written reminder notices were placed in all of the nurses mail boxes at the agency without the DNE.

Patient records were studied retrospectively. In each agency, a computer generated list was obtained. It included patients with diabetes documented as either the primary or secondary diagnoses, who were discharged from the agency 3 months before the data collection. Patient names were not recorded. The sample size was the first 20 available records at each agency that met the criteria. Pediatric patients were excluded from the sample and also excluded were those patients whose major focus for their plan of care was not related to diabetes.

\section{Human Subjects Approval}

Human subjects approval was obtained for this research study from the San Jose State University Institutional Review Board in May 1995 (Appendix E). The nurses who participated in this study received a packet that included a cover letter explaining the study, the Agreement to Participate in Research, the Nurse Information Questionnaire, and the Diabetes: Basic Knowledge Test. Written approval was obtained from the directors of patient care and the research committees at the two home care agencies following a written and/or verbal presentation of the proposed study. All patient sensitive data was destroyed by shredding at the end of the study.

\section{Instruments}

The instruments used were the same four data collection forms used in the study by Adams and Cook (1994). They were the Diabetes: Basic Knowledge Test (DBKT) (Appendix A), the Nurse Information Questionnaire, (NIQ) (Appendix B), the Nursing Care Intervention Tool (NCIT) (Appendix C), and the Patient Characteristics Questionnaire (PCQ) (Appendix D).

The Nurse Information Questionnaire (NIQ), as developed by Adams and Cook (1994), was used to obtain demographic and clinical practice data regarding the nurses participating in the study. The NIQ was copied with permission (Appendix E) and for this 
study had one additional question regarding the Diabetes Control and Complications Trial.

The self-administered, multiple choice Diabetes: Basic Knowledge Test (DBKT) was initially developed by Scheiderich et al. (1983) to test nurses' knowledge about care of patients with diabetes. It was modified by Drass et al. (i989) and updated by D. L. Jameson and copied with permission (personal communication November 10, 1994 Appendix E). The DBKT was further modified for this study to include updated information for both Type I and Type II diabetes and to reflect care of the diabetic patient in the home care setting. The DBKT used for this study contained 44 items and gave a total score correct of the nurse's knowledge about diabetes. According to Adams and Cook (1994), the DBKT was originally validated by Drass et al. and had an internal consistency of .79 .

The Patient Characteristic Questionnaire (PCQ), as developed by Adams and Cook (1994), was used to obtain confidential patient demographic and clinical information. The PCQ was copied with permission (Appendix E) and slightly modified to include the discharge location of Skilled Nursing Facility (SNF) rather than Extended Care Facility (ECF). The IDDM and NIDDM terminology for Type I and Type II, respectively, was used to be consistent with the International Classification of Diagnosis -9 Clinical Modifications (ICD-9-CM codes) (1994) used in the patient record. The Strock Level of Care was obtained at the start of care and at discharge. On both admission to the home health agency and discharge from the home health agency blood pressure and blood glucose levels were obtained.

A retrospective audit of the records of home care patients with diabetes was done at the two home health agencies to complete the Nursing Care Intervention Tool (NCIT). This tool measured the outcomes of the level of nursing care provided to patients with diabetes at a home health agency. It was developed by Adams and Cook (1994) and was found by them to have an average interrator reliability of .93 . The NCIT was originally designed for use with IDDM patients only and for this study these words were eliminated from the title. It was also copied with permission (Appendix E) and modified to indicate where the 
information could be found in the records of the two home health agencies being used for this study. There were no other changes in this study's research design.

\section{Data Collection}

The data were gathered by one researcher between July 1995 and September 1995. Each nurse participant completed the Diabetes: Basic Knowledge Test (DBKT) and the Nurse Information Questionaire (NIQ) and deposited them anonymously and voluntarily into the envelopes left in the nursing education office for this purpose. The chart review at both agencies was conducted using the Patient Care Characteristics Questionnaire (PCQ) and the Nursing Care Intervention Tool (NCIT).

\section{Analysis of Data}

The NCIT was scored using the same methodology as Adams and Cook (1994); "the total number of NA responses was subtracted from the total number of items. The number of 'Yes' responses then was divided by the number of items that applied to the patient to obtain a percentage scure" (p. 50).

The data for this study were analyzed using the Microsoft Excel (1994) computer program to obtain the descriptive statistics to describe the mean scores and inferential statistics to do independent sample t-tests of the data collected. According to DePoy and Gitlin (1994), the t-test is a "parametric test to find out the extent to which any significant differences existing between two sample group means can be inferred to the population" (p. 306).

The results of the DBKT and the NCIT were determined by using the means and the t-tests. The data from the NIQ and the PCQ were analyzed using the mean and the standard deviations for the following: age of the patients, nursing visits per month to diabetic patients, nurses' number of years at the home health agency, nurses' years in home health care, and years of nursing experience. The results obtained from this study were then analysed to determine their significance. 


\section{Chapter 4}

\section{ANALYSIS AND INTERPRETATION OFDATA}

The purpose of this study was to determine if having a diabetes nurse educator (DNE) at a home health agency made any difference in the knowledge that nurses had about diabetes or the nursing care that they provided to patients with diabetes. The level of significance was set at $\mathrm{p}<.05$. This chapter is an analysis of the data collected from the questionnaires completed by the nurses at the two home health agencies and the patient records reviewed at these same two agencies.

There were 104 copies of the Nurse Information Questionnaire (NIQ) and the Diabetes: Basic Knowledge Test (DBKT) distributed to the nurses at the agency with the DNE. There were 24 nurses who responded, for a response rate of $23 \%$. At the agency without a DNE, there were 68 copies distributed and 25 were returned, for a response rate of $37 \%$.

The scores of the two samples of the DBKT were essentially the same for both agencies, as shown in Table 1.

Table 1

Diabetes: Basic Knowledge Test Scores for the Samples

\begin{tabular}{llll}
\hline & $\underline{\mathrm{N}}$ & $\underline{\mathrm{M}}$ & $\underline{\mathrm{SD}}$ \\
\hline $\begin{array}{l}\text { Agency with Diabetes } \\
\text { Nurse Educator }\end{array}$ & 24 & 34 & 4.78 \\
$\begin{array}{l}\text { Agency without Diabetes } \\
\text { Nurse Educator }\end{array}$ & 25 & 33.9 & 3.43 \\
\hline
\end{tabular}

The independent t-test was conducted for the DBKT mean scores of the two samples with the level of significance set at $\mathrm{p}<.05$. The results yielded a very small $\underline{t}$ value 
of 0.07 with a df of 47 and a $\mathrm{p}$ of .95 . This showed that there was no statistically significant difference between the scores for the two agencies and therefore the first rescarch question was not supported.

These results were different from those obtained by Adams and Cook (1994). They found that the nurses at the agency with the diabetes nurse educator (DNE) scored significantly higher on the Diabetes: Basic knowledge Test (DBKT) than the nurses without the DNE.

The results of the Nursing Care Intervention Tool (NCIT) scores, which measured the level of nursing care provided to patients at the two home health agencies, are shown in Table 2. An independent t-test was conducted of the means of the two samples with the

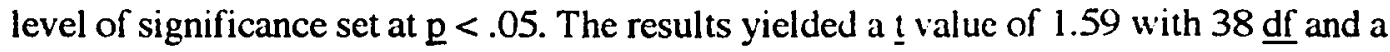
$\mathrm{p}$ of .123. This data showed that there was no statistically significant difference between the two agencies and that the agency without the DNE actually scorcd higher than the agency with the DNE. These data did not support the sccond rescarch question. This is directly opposite from the results found by Adams and Cook (1994).

Table 2

Nursing Care Intervention Tool Scores for the Samplc

\begin{tabular}{llll}
\hline & $\underline{\mathrm{N}}$ & $\underline{\mathrm{M}}$ & $\underline{\mathrm{SD}}$ \\
\hline $\begin{array}{l}\text { Agency with Diabetes } \\
\text { Nurse Educator }\end{array}$ & 20 & 80.2 & 22.54 \\
$\begin{array}{l}\text { Agency without Diabetes } \\
\text { Nurse Educator }\end{array}$ & 20 & 89.3 & 12.54 \\
\hline
\end{tabular}

Some of the demographic data from the Nurse Information Questionnaire (NIQ) for the two samples are summarized in Table 3 using mean data. The agency without the DNE 
made approximately twice the number of visits per month to patients with diabetes. This may have been related to the reimbursement for the visits. The majority of the visits by the agency with the diabetes nurse educator (DNE) were paid for by private insurance companies that required prior authorization for each visit and usually resulted in fewer visits. The majority of the visits by the agency without the DNE were reimbursed by Medicare which is less restrictive on the number of visits made and does not require prior authorization. Another reason more visits were made by the nurses at the agency without the DNE was that more of their patients were in the Level I Strock Level of Care as discussed by Strock, Jacobson, Reader, and Hollander (1988). This level identified patients who were newly diagnosed as diabetic or who were new on insulin and therefore required more nursing visits until they were independent with their diabetic regimen. The nurses for both samples had a similar number of years at their respective agencies and similar number of years in home care. The nurses at the agency with the diabetes nurse educator (DNE) had more years of nursing experience than the agency without the DNE. Table 3

Demographic Data from the Nurse Information Questionnaire

\begin{tabular}{|c|c|c|c|c|}
\hline \multirow[t]{2}{*}{ Variable } & \multicolumn{2}{|c|}{$\begin{array}{l}\text { Agency with DNE } \\
\qquad(\underline{n}=23)\end{array}$} & \multicolumn{2}{|c|}{$\begin{array}{l}\text { Agency without DNE } \\
\qquad(\underline{n}=24)\end{array}$} \\
\hline & $\underline{\mathrm{M}}$ & $\underline{\mathrm{SD}}$ & $\underline{\mathrm{M}}$ & $\underline{\mathrm{SD}}$ \\
\hline Visits / month to Diabetes patients & 10.43 & 10.65 & 17.64 & 18.72 \\
\hline Years at HHA & 3.09 & 5.07 & 3.69 & 3.74 \\
\hline Years in Home Care & 4.18 & 5.12 & 4.26 & 4.07 \\
\hline Years of Nursing experience & 19.63 & 9.43 & 14.06 & 9.57 \\
\hline
\end{tabular}

The data obtained from the Nurse Information Questionnaire (NIQ) revealed other differences between the nurses at the two agencies. More of the nurses at the agency with 
the diabetes nurse educator (DNE) reported attending diabetes inservice classes within the past 6 months and also within the past 2 years compared to the nurses at the agency without the DNE. Of the nurses responding at the agency with the DNE, seven had a Master of Science degree in nursing compared to only one nurse at the agency without a DNE. There were almost twice the number of nurses (i.e., fifteen nurses) at the agency without a DNE who reported that they had never heard of the Diabetes Control and Complications Trial or its results, compared to only nine nurses at the agency with a DNE.

The Patient Characteristics Questionnaire (PCQ) used with the Nursing Care Intervention Tool (NCIT) for the review of 20 patient records at each agency showed several areas of similarity. There was a mean age of 73 years for patients at both agencies. All but one of the patients studied had Type II diabetes and most of the patients were on insulin therapy. Both groups had more females in the sample than males, which corresponds to the general population statistics for this age group. Most of the patients in both groups were either married or widowed.

Table 4

Comparison of Admission and Discharge Blood Glucose Readings

\begin{tabular}{|c|c|c|c|c|c|c|}
\hline \multirow[t]{2}{*}{ Variable } & \multicolumn{3}{|c|}{ Agency with DNE } & \multicolumn{3}{|c|}{ Agency without DNE } \\
\hline & $\underline{\mathbf{n}}$ & $\underline{\mathrm{M}}$ & $\underline{\mathrm{SD}}$ & $\underline{\mathbf{n}}$ & $\underline{M}$ & $\underline{\mathrm{SD}}$ \\
\hline Admit Blood Glucose & 17 & $180 \mathrm{mg} / \mathrm{dl}$ & 71 & 20 & $224 \mathrm{mg} / \mathrm{dl}$ & 69 \\
\hline Discharge Blood Glucose & 13 & $142 \mathrm{mg} / \mathrm{dl}$ & 42 & 18 & $166 \mathrm{mg} / \mathrm{dl}$ & 53 \\
\hline
\end{tabular}

Table 4 reveals that the mean random admission and discharge blood glucose levels at both agencies were similar. These values are considerably above the values suggested by the American Diabetes Association in their Standards of Medical Care for Patients with Diabetes Mellitus (1995 b) for before meal blood glucose levels of less than $120 \mathrm{mg} / \mathrm{dl}$, 
whether they are insulin dependent diabetics or non-insulin-dependent diabetes. A future study could be done using blood glucose levels as an outcome measure of the level of nursing care provided to diabetics by home care agencies with and without a diabetes nurse educator (DNE).

The Patient Information Questionnaire (PIQ) also showed that of the patient records audited, there were more referrals of patients to the home health agency from the hospital at the agency with the DNE and more referrals from non-hospitalized patients at the agency without the DNE. Eighteen of the 20 patients' records audited at the agency with the DNE had English as their primary language, compared to only 11 of the 20 patients at the agency without the DNE. The following chapter provides conclusions and future recommendations, as a result of these findings. 


\section{Chapter 5}

\section{CONCLUSIONS AND RECOMMENDATIONS}

The purpose of this study was to determine if the findings of the Adams and Cook (1994) study could be replicated in a different location to determine if nurses had a higher level of knowledge of diabetes and provided a higher level of care in a home health agency employing a diabetes nurse educator. The literature review supported the role of the DNE but there were no other studies that studied the effects of the diabetes nurse educator (DNE) on improving diabetic patient care outcomes or if the DNE resulted in nurses having an increased knowledge about diabetes. In this chapter the conclusions, limitations of the study, and recommendations for future nursing research will be discussed.

\section{Conclusions}

The data analyses showed that there were no differences in the scores on the DBKT between the nurses who worked in an agency with a DNE and the nurses who worked in an agency without a DNE. These findings do not support the first research question or the conceptual framework using the Linkage Model with the role of the DNE acting as the link between information about diabetes and the stafí nurses' knowledge about diabetes.

Drass, Muir-Nash, Boykin, Turek, and Baker (1989) stated that unless nurses update themselves every 6 months about diabetes their knowledge will not be current. If this were true for the nurses' ongoing diabetic education at the agency with the DNE, it would have been expected that they would have scored higher on the Diabetes: Basic Knowledge Test (DBKT). For this study, it was expected that the agency with the DNE would reflect a higher level score on the DBKT, especially since more of these nurses reported attending a diabetes continuing education program within the past 2 years and in the past 6 months as compared to the agency without the DNE.

Twice as many nurses employed at the agency using a DNE who responded to the Nurse Information Questionnaire (NIQ) reported that they knew about the results of the Diabetes Control and Complications Trial (DCCT) study results, which was an important 
relatively new development for diabetes management. These nurses, therefore, might have been expected to score higher on the Diabetes: Basic Knowledge Test (DBKT).

The nurses who did not respond to the questionnaire may have negatively contributed to the true score value because they chose not to respond. There was a higher than expected rate of non-response or self-selection. Despite repeated requests to complete the questionnaire at both agencies, few were returned.

It was expected that the agency with the diabetes nurse educator (DNE) also would have had better results on the Nursing Care Intervention Tool (NCIT) than the agency without the DNE. The data did not show that there was any statistically significant difference between the two agencies and did not demonstrate that there was a higher level of care to patients with diabetes at the agency that had a DNE. The second research question was not supported by the data. It was expected that even if the DNE and the diabetes team did not see all the diabetic patients, their availability for consultation and educational sessions would have resulted in a higher score on the NCIT. Both agencies had diabetic flow sheets, or caremaps, that were used on some, but not all records; these flow sheets did not seem a factor in the results of the study. If more records were reviewed, by expanding the period to patients discharged in the 6 months before data collection rather than merely 3 months before data collection, it is possible that the results might have been different.

Adams and Cook (1994) discussed the implications for their study results as they reiated to the scope of practice standards developed by the Task Force of the American Association of Diabetes Educators (1992) for DNE's. These standards focused on the role of the DNE with patients and their caregivers and did not discuss developing the role of the DNE for educating staff nurses about the latest developments and techniques in diabetes management. Adams and Cook (1994) concluded that a more viable role for the DNE would be to expand the scope of the DNE's practice to include these areas.

The results of this study revealed that if a role of the DNE in home care is to 
increase all the nursing staff's knowledge about diabetes, the diabetes nurse educator (DNE) may be most effective as an educator and consultant to the staff, rather than the leader of a team of nurses that only sees diabetic patients. As the population ages and the incidence of diabetes increases, diabetes will be a more frequent reason for home care admissions. Further research would need to be done by repeating this study with a larger nurse respondent pool and larger patient population groups at the same home health agency and at other agencies, using this same methodology, to see if the DNE does make a difference.

\section{Limitations}

A limitation to this study was that the nonexperimental research design does not allow for conclusions or generalizations that the DNE was responsible for the results of the Diabetes: Basic Knowledge Test (DBKT) scores or the results of the Nursing Care Intervention Tool (NCIT). LoBiondo-Wood and Haber (1994) stated that "if a sample size is representative of the population, a relatively small number of respondents can provide an accurate picture of the target population" (p. 235). Despite this statement, the small number of nurses who responded to the DBKT and the small number of records reviewed retrospectively for the NCIT may have been limitations of this study. There was no attempt made to match the two agencies for extraneous variables such as the nurse's number of years experience in nursing, nurses' educational levels, and number of years in home health care. However, their years of experience in home care are similar.

\section{Recommendations}

A method to increase the response rate for the Nurse Information Questionnaire (NIQ) and the DBKT would need to be chosen to improve the statistical significance of future replication of the Adams and Cook (1994) methodology. Using more than 20 patients for the record review also would increase the reliability of comparisons of the Patient Characteristics Questionnaire (PCQ) and NCIT.

The relationship between the DNE's presence and patient outcomes was not the focus of this study, but it should be an important consideration for future studies. The third 
party payers of health care are interested in which agency can provide the best patient outcomes for the least amount of cost. Improved diabetic patient outcomes have major implications for reducing costs of health care. It would be hoped that the diabetes nurse educator (DNE) is the professional who can facilitate this process for diabetic patients.

This study should be further replicated using Adams and Cook's (1994) methodology, to determine if the results of this study were an unusual occurrence. Another recommendation would be to repeat this study and to include a methodology to evaluate whether the DNE role and improved patient outcomes are positively correlated and are more cost effective. The diabetes nurse educator could teach nurses about diabetes in the traditional inservice education class model. This could be compared to a diabetes nurse educator doing individual teaching to patients or nurses about diabetes management.

In these times of health care reform and developments of new systems for delivering health care in a cost-effective and expedient manner, it is important that nursing management of patients with diabetes be studied. Diabetes is of ten a diagnosis present in the home care population. According to the original study done by Adams and Cook (1994), the DNE is the link between the knowledge and technical expertise about diabetes management and the home care nurse, home care patients, and caregivers and will become increasingly important as the health care system seeks ways to increase quality of health care and reduce costs. That this study did not have similar findings to Adams and Cook (1994) does not necessarily show that there is no need for the DNE. More studies using methodologies similar to this study will give clarification to how the DNE will assist home health agency's to optimize the patient's diabetic management and optimize nurse's knowledge of diabetes. 


\section{References}

Adams, C. E., \& Cook, D. L. (1994). The impact of a diabetes nurse educator on nurses' knowledge of diabetes and nursing interventions in a home care setting. The Diabctes Educator, 20, 49-53.

American Diabetes Association. (1995 a). Self-monitoring of blood glucose. Diabetes Care, 18, Supp. 1, 47-52.

American Diabetes Association. (1995 b). Standards of medical care for patients with diabetes mellitus. Diabetes Care, 18, Supp. 1, 8-15.

American Diabetes Association. (1995 c). Urine glucose and ketone determinations. Diabetes Care 18, Supp. 1, 20.

American Diabetes Association. (1993). Diabetes: 1993 vital statistics. Alexandria,VA: American Diabetes Association.

Cypress, M., Wylie-Rosett, J., Engel, S.S., \& Stager, T.B. (1992). The scope of practice of diabetes educators in a metropolitan area. The Diabetes Educator, 18, 111-114.

Davis, E. D. (1990). Role of the diabetes nurse educator in improving patient education. The Diabetes Educator, 16, 36-38.

Depoy, E. \& Gitlin, L. N. (1994). Introduction to research. St. Louis: Mosby.

Diabetes Control and Complications Research Group. (1993). The effect of intensive treatment of diabetes on the development and progression of long term complications in insulin-dependent diabetes mellitus. New England Journal of Medicine, 329, 977-986.

Diabetes Control and Complications Research Group. (1987). Diabetes control and complications trial (DCCT): results of feasibility study. Diabetes Care, 10, 1-19.

Drass, J. A., Muir-Nash, J. Boykin, P. C., Turek, J. M., \& Baker, K. L. (1989). Perceived and actual level of knowledge of diabetes mellitus among nurses. Diabetes Care, $\underline{5} 351-356$. 
Dudley, J. D. (1980). The diabetic educator's role in teaching the diabetic patient. Diabetes Care, 3, 127-133.

Etzwiler, D. D. (1967). Who is teaching the diabetic? Diabetes, 16, 111-117.

Etzwiler, D. D. (1994). Primary-care teams and a systems approach to diabetes management. Clinical Diabetes, 12, 50-52.

Franz, M.J., Callahan, T., \& Castle, G. (1994). Changing roles: Educators and clinicians. Clinical Diabetes, May/June, 53-54.

Funnell, M. M. (1990). Role of the diabetes educator for older adults. Diabetes Care, $13,60-65$.

Girouard, S. (1983). Theory-based practice: Functions, obstacles, and solutions. In Hamric, A. B., \& Spross, J. (Eds.), The clinical nurse specialist in theory and practice (pp. 21-37). New York: Grune \& Stratton.

Gossain, V.V., Bowman, K.A., \& Rovner, D. R. (1993). The actual and selfperceived knowledge of diabetes among staff nurses. The Diabetes Educator, 19, 215-219.

Havelock; R. G. (1971). Planning for innovation. Ann Arbor, MI: Institute for Social Research.

Jayne, R.L., \& Rankin, S.H. (1993). Revisiting nurse knowledge about diabetes: An update and implications for practice. The Diabetes Educator, 19, 497-502.

Jornsay, D., \& Cypress, M. (1994). Tight control: The new standard of care. Diabetes Self-Management, January/February, 22-24.

Lebovitz, H. E., \& Vinik, A. I. (1991) Workshop VIII-Retinopathy, nephropathy, neuropathy, and tight control. The American Journal of Medicine, 90, (Suppl. 2A), 815835.

LoBiondo-Wood, G., \& Haber, J. (1994). Nursing research: Methods, critical appraisal, and utilization (3rd ed.). St. Louis: Mosby.

Microsoft Excel Version 5.0c [Computer software]. (1994). Redmond, WA. 
Minaker, K.L. (1990). What diabetologists should know about elderly patients. Diabetes Care, 13, (Suppl. 2), 34-46.

Morley, J. E., \& Perry, H. M. (1991). The management of diabetes mellitus in older individuals. Drugs, 41, 548-565.

Muchmore, D.B. (1994). Is there a role for self-monitoring of blood glucose in type II diabetes? Practical Diabetology, 13, (4), 7-9.

National Certification Board for Diabetes Educators (1992). Certification examination for diabetes educators: Handbook for candidates. (Brochure). Professional Testing Corporation.

National Institute of Diabetes and Digestive and Kidney Diseases. (1994). Diabetes statistics. (U.S. Department of Health and Human Services Publication No. 94-3822). Washington, DC: U.S. Government Printing Office.

Peragallo-Dittko, V., Godley, K., \& Meyer, J. (Eds.). (1993). A core curriculum for diabetes education. (2nd ed.). Chicago: American association of diabetes educators.

Reichard, P., Britz, A.,, Carlsson, P., Cars, I., Lindblad, L., Nilsson, B. Y., \& Rosenqvist, U. (1990). Metabolic control and complications over three years in patients with insulin dependent diabetes (IDDM): The Stockholm diabetes intervention study (SIDS). Journal of Internal Medicine, 228, 511-517.

Reichard, P., Toomingas, B., \& Rosenqvist, U. (1994). Changes in conceptions and attitudes during five years of intensified conventional insulin treatment in the Stockholm diabetes intervention study (SDIS). The Diabetes Educator, 20, 503-514.

Rubin, R.J., Altman, W.M., \& Mendelson, D.N. (1994). Health care expenditures for people with diabetes mellitus, 1992. Journal of Clinical Endocrinology and Metabolism, 78, 809A- 809F.

Scheiderich, S. D., Freibaum, C. N. \& Peterson, L. M. (1983). Registered nurses' knowledge about diabetes mellitus. Diabetes Care, 6, 57-61. 
Strock, E., Jacobson, J., Reader, D., \& Hollander, P. (1988). Managing diabetes in the home: A model approach. Caring, $7_{2}(2), 50-56$.

Task Force of the American Association of Diabetes Educators. (1992). Scope of practice for diabetes educators and standards of practice for diabetes educators. The Diabetes Educator, 18, 52-56.

U.S. Department of Health and Human Services. (1994). International classification of diseases \#9 clinical modifications, 5th ed. Washington: DC: St. Anthony Press. 
Appendix A

Diabetes: Basic Knowledge Test (DBKT) 
Diabetes: Basic Knowledge Test

1. Which statement is characteristic of the cause of Type I diabetes?

a. strongly associated with obesity

b. predominantly genetic

c. autoimmune, viral, or toxic destruction of the beta cells

d. I do not know

2. Which of these statements about the management of Type I diabetes is true?

a. insulin injections are necessary to maintain life

b. insulin injections are not always necessary to maintain life if diet and exercise are well controlled

c. oral hypoglycemic agents are sufficient for blood glucose control in most patients

d. I do not know

3. Which statement is characteristic of the cause of Type II diabetes?

a. predominantly non-genetic

b. frequently associated with obesity and resistance to insulin

c. autoimmune, viral, or toxic destruction of the beta cells

d. 1 do not know

4. Which of these statements about management of Type II diabetes is true?

a. insulin injections are necessary to maintain life

b. a controlled diet and exercise program is the most effective treatment

c. oral hypoglycemic agents are always effective as a treatment

d. I do not know 
5. What effect does insulin have on the blood glucose?
a. insulin causes blood glucose to increase
b. insulin causes blood glucose to decrease
c. insulin has no effect on blood glucose
d. I do not know

6. What are the physiological actions of insulin?
a. transports glucose across cell membranes for use by the cells
b. slows the rate of glycogen storage in the liver, muscle, and other tissues
c. enhances the breakdown of fat cells into free fatty acids that are used for energy
d.I do not know

7. If a known diabetic is found unresponsive, which of the assumptions about the person's blood glucose should guide your initial actions?
a. blood glucose may be very high
b. blood glucose may be very low
c. blood glucose may be normal
d. I do not know

8. Normal fasting blood glucose level is:
a. below $150 \mathrm{mg} / \mathrm{dL}$
b. between 100 and $200 \mathrm{mg} / \mathrm{dL}$
c. between 70 and $120 \mathrm{mg} / \mathrm{dL}$
d. I do not know

9. The current recommendation for the site of insulin administration is the:
a. abdomen only
b. thighs only
c. rotate between abdomen, thighs, and arms
d. I do not know 
10. A symptom of hypoglycemia is:
a. frequent urination
b. dry mouth and dry skin
c. nervousness
d. I do not know

11. A symptom of hyperglycemia is:
a. sweating, cool or clammy skin
b. headache
c. frequent urination
d. I do not know

12. Which of the following is most likely to affect the accuracy and precision of test results obtained with blood glucose monitoring meters?
a. quality control tests have been performed on the meter daily
b. when the meter results compare accurately with another meter
c. size and placement of the blood sample on the test strip
d. I do not know

13. Which of the following tests can determine the patient's average blood glucose control over an extended period of time?
a. glycosylated hemoglobin ( $\mathrm{HbA} 1 \mathrm{c})$
b. C-peptide
c. insulin antibodies
d. I do not know 
14. Which of these statements indicates one of the best reasons for using blood glucose monitoring rather than urine testing?

a. drugs such as penicillins, ASA, cephalosporins, barbiturates, etc. can create falsely negative urine test results

b. urine retention and changes in kidney function can increase the lag time between blood glucose rise and spill over of glucose into the urine

c. diagnosis of diabetes can be more readily confirmed at the patient's bedside with blood glucose monitoring than by laboratory testing

d. I do not know

15. In the diabetic patient recovering from surgery, maintaining blood glucose levels as close as possible to the normal range is important because:

a. high blood glucose levels are associated with impaired response to infection and poor wound healing

b. low blood glucose levels can lead to ketoacidosis and electrolyte imbalances

c. high and low blood glucose levels may increase the length of the recovery

d. I do not know

16. Diabetic ketoacidosis can:

a. occur in Type I diabetics only

b. occur in Type II diabetics only

c. occur in Type I and II diabetics

d. I do not know

17. Hyperglycemic hyperosmolar nonketotic syndrome can:
a. occur in Type I diabetics only
b. occur in Type II diabetics only
c. occur in Type I and II diabetics
d. I do not know 
18. When should a person with Type I diabetes check the urine for ketones?
a. before exercising
b. every day
c. when the blood glucose is over $240 \mathrm{mg} / \mathrm{dL}$
d. I do not know

19. What should the Type I diabetic do if the blood glucose is over $240 \mathrm{mg} / \mathrm{dL}$ for two days and the urine is positive for ketones?
a. continue with usual insulin dose as these are normal results
b. omit the next dose of insulin and continue to test the blood glucose and urine for ketones
c. call the doctor and continue to take insulin and to test blood glucose and urine for ketones every 4 hours
d. I do not know

20. The maximum effect (peak) of regular insulin occurs:
a. 2-4 hours after injection
b. 6-12 hours after injection
c. 16-24 hours after injection
d. I do not know

21. The maximum effect (peak) of both NPH and Lentc insulin cecurs:
a. 2-4 hours after injection
b. 6-12 hours after injection
c. 16-24 hours af ter injection
d. I do not know 
22. Where should insulin that is currently being used be stored?
a. in the refrigerator door to prevent freezing
b. at room temperature
c. on the window sill exposed to direct sunlight
d. I do not know

23. A person with diabetes contaminates the needle of the syringe while preparing an insulin injection. What would be the best action to take?
a. dispose of the syringe and prepare another syringe
b. wipe the needle with an alcohol sponge and inject the insulin
c. use the syringe but wipe the injection site thoroughly with alcohol
d. I do not know

24. When regular and NPH insulin are to be given at the same time, the nurse should:
a. use separate syringes to administer each insulin
b. mix them in the same syringe drawing up the NPH insulin first
c. mix them in the same syringe dratving up the regular insulin first
d. I do not know

25. The duration of action of glyburide (Diabeta, Micronase, Glynase) and glypizide (Glucotrol), is:
a. 6-12 hours
b. 12-18 hours
c. 24 hours
d. I do not know

26. Which is not a reported side effect of oral hypoglycemic agents?
a. nausea, vomiting
b. skin rash
c. hyperglycemia
d. I do not know 
27. What is one cause of hypoglycemia?
a. skipping meals
b. emotional stress
c. too little exercise
d. I do not know

28. What is one cause of hyperglycemia?
a. decreased food intake
b. infection
c. excessive insulin
d. I do not know

29. What is one symptom of diabetic ketoacidosis?
a. cold, clammy skin
b. acetone (fruity) breath
c. negative urine for ketones
d. I do not know

30. What is a cause of diabetic ketoacidosis?
a. excessive exercise
b. excessive intake of diet soft drinks over a prolonged period
c. failure to take daily dose of insulin
d. I do not know

31. What effect does illness have on insulin requirements?
a. causes a decrease in insulin requirements
b. causes an increase in insulin requirements
c. causes no changes in insulin requirements
d. I do not know 
32. Which of the following is not a complication of diabetes?
a. retinopathy
b. deep vein thrombosis
c. neuropathy
d. nephropathy

33. Physical and emotional stress causes the following effect on diabetes control:
a. secretion of stress hormones causing an elevation of blood glucose
b. secretion of stress hormones causing a decrease of blood glucose
c. secretion of stress hormones has no effect on blood glucose levels
d. I do not know

34. Why is it necessary that diabetics pay special attention to the care of their feet?
a. several years of injecting into the thighs can cause edema in the feet
b. flat feet are commonly associated with diabetes and can be prevented
c. diabetics of ten have changes in sensation and poor circulation to their feet
d. I do not know

35. A person with diabetes wants a small corn on their foot removed. They should first:
a. use a liquid corn remover, following the directions carefully
b. make an appointment with a podiatrist
c. carefully trim the corn with a sterile cutting instrument
d. I do not know 
36. A person with diabetes has just received a minor abrasion on the left lower leg. They should:

a. wash gently with mild soap and water, dry with a clean towel, and observe carefully for any signs of infection and if present call the doctor

b. go to the nearest emergency room

c. wash gently with mild soap and water, dry with a clean towel, and apply a small amount of betadine

d. I do not know

37. What effect does exercise have on blood glucose if it is below $250 \mathrm{mg} / \mathrm{dL}$ ?
a. decreases blood glucose
b. increases blood glucose
c. has little effect on blood glucose
d. I do not know

38. Which is the most appropriate initial treatment for hypoglycemia?
a. take 3 - 4 glucose tablets or drink 4 oz. regular soda
b. drink 4 oz. orange juice with 2 tsp. sugar
c. eat a chocolate bar
d. I do not know

39. The major goal of meal planning for a patient with diabetes is to:
a. assist with normalization of bload glucose levels
b. divide carbohydrates into equal percentages throughout the day
c. increase protein reserves with a high carbohydrate, high protein diet
d. I do not know 
40. A diabetic diet is calculated for which of the following nutrients:
a.meats, fruits, vegetables, milk and breads
b. carbohydrates, proteins, and fats
c. proteins, grains, and milk products
d. I do not know

41. A diabetic patient taking insulin refuses an evening snack of fruit juice and one half of a sandwich. You should substitute with:
a. five graham crackers and $8 \mathrm{oz}$. plain yogurt
b. six crackers and $2 \mathrm{oz}$. of cheese
c. a piece of fresh fruit, $1 \mathrm{oz}$. of peanut butter and six crackers
d. I do not know

42. A well controlled Type I diabetic patient who exercises usually needs:
a. less food
b. more food
c. the same amount of lood
d. I do not know

43. For the past 2 days a diabetic patient has had:

-wide fluctuations in blood glucose (BG) levels over several hours, of ten unrelated to meals

-elevated fasting BG levels, preceded by nocturnal sweating, nightmares, or headache

-3 AM BG level of 40 followed by 8 AM BG level of 320

This patient is exhibiting symptoms of:
a. Pass-through or flashback phenomenon
b. Somogyi or rebound effect
c. Dawn phenomenon
d. I do not know 
44. According to the Diabetes Control and Complications Study (DCCT), patients with Type I diabetes can decrease their risk of chronic complications of diabetes by:
a. eating a high carbohydrate diet
b. maintaining as near normal blood glucose levels as possible
c. eating a high fat diet
d. I do not know

THE END. When you have completed the Diabetes: Basic Knowledge Test and the Nurse Information Questionnaire, return them to the labeled box/envelope in the Inservice Educators office. Thank you for your participation.

Source of the test: "Diabetes: Basic Knowledge Test", developed by Sandra D.

Scheiderich, Carol N. Freibaum, and Leona M. Peterson, 1983. The test was modified by Janice A. Drass, Joanne Muir-Nash, Priscilla C. Boykin, and Karen L. Baker, 1989. The content was further updated and modified by Denise L. Jameson and Jayne F. Moore, 1993 and by Valerie Isaacson, 1995. Used with permission of Denise L.Jameson, 1994. 
Appendix B

Nurse Information Questionnaire (NIQ) 


\section{NURSE INFORMATION QUESTIONNAIRE}

1. Number of years nursing experience

2. Number of total years in home health care

3. Number of hours / week worked or days / month

4. Number of years at current home health care agency

5. Highest education preparation obtained in nursing: (circle)

a) Diploma b) Associate Degree c) BSN Degree d) MSN Degree

6. Have you achieved certification in any area of nursing practice?

No Yes , If yes, in what area

7. I most recently attended an inservice/continuing education program in Diabetes:

a) none b) within the last 6 months c) more than 6 months but less than 1 year ago d) more than 1 year ago but less than 2 years ago e) more than 2 years ago

8. The number of my visits to patients who have diabetes in the past:

a) week was: b) month was:

9. If you subscribe to a professional journal (s), Please list:

10. Circle how comfortable you are in caring for a patient who has diabetes.

( 1 = least comfortable, $5=$ most comfortable) * $1212345 \%$

11. With regard to the 1993 results of the Diabetes Control and Complications Trial:

a) I have never heard of this study.

b) I have read an article about the results in the past year.

c) It was discussed at a continuing education program that I attended in the past year.

Used with permission of David L. Cook, 1994.

Modified by Valerie Isaacson, 1995. 
Appendix C

Nursing Care Intervention Tool (NCIT) 
NURSING CARE INTERVENTION TOOL

Directlons: Mark yes or ne or nonapplicable (NA) to each of the assessment questions on the Tool, Note: Numbering is such that a Scan sheet may be used.

1. ADMISSION ASSESSMENT: This information is usually listed on an admission assessment form or HCFA form.

\begin{tabular}{|l|l|l|}
\hline Yes & No & NA \\
\hline
\end{tabular}
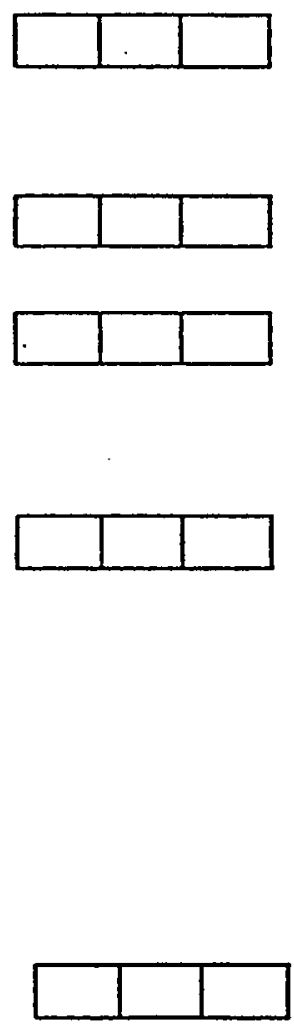

A. Problem Identification: Is documentation present that indicates assessment for behavioral deficits/problems such as those listed under $1-4$ below. (Mark a check in the Yes column if even one item listed in each of the following is present.)

1. Knowledge deficits such as blood glucose monitoring. diet, medication administration and use. acute emergencies, safety measures, other self-care skills.

2. Soclal/cultural problems such as lack of support system, transportation, money. Insurance.

3. Psychological deficits/ problems such as thought process and judgement, mental status. abllity to learn. forgetfulness/confusion, competing values, grieving. process.

4. Physiological deficits/problems such as visual. dexterity, hearing. mobllity. ADL problems, wounds. cardiopulmonary, neurologic and blood glucose level.

B. Admission Teaching: Minimal instruction is Initiated. Usually, instruction consists of demonstrations and introductory discussions of safety measures. survival skdlls (medication administration. blood glucose monitoring procedure. dietary highlights, and treatment of hypoglycemia): and answering of client questions.

5. One to three toplcs listed above are documented: safety measures, survival skulls, or answertng of cllent questions. 

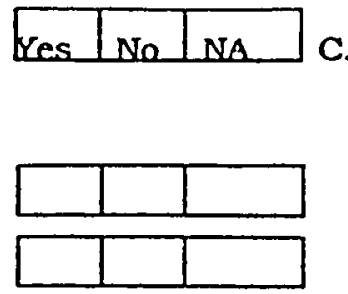

C.

Admission Treatments: glucose monltoring. Insulln administration, phone call to $\mathrm{MD}$ for high risk blood sugar levels. adjustment of insulln per suding scale and etc.

6. A blood glucose level was obtalned during visit.

7. Mark Yes if any one of the following treatments were documented on the admission visit:

a. Insulin was pre-drawn by RN.

b. Cllent was assisted with drawing and infecting the insulin.

c. Phone call to $\mathrm{MD}$ to give status report or report high risk blood sugar levels ( $<80$ or $>240 \mathrm{mg}$.).

Mark No if the clinical findings and planned care indicates that a treatment was efther missed or not documented.

Mark NA If no treatments were indlcated.

D. Admit Evaluation: The evaluation is the clinical Findings on the HCFA form. or clati buse.

8. One or more potentlal or actual risk factors such as safety. noncomplance. knowledge deficits, physical and/or mental signs and symptoms are listed.

II. PLAN

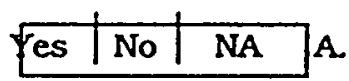

Is there a written nursing care plan (If Yes answer numbers 1-6. If No go to III. Documentation).

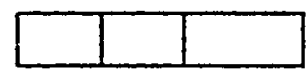

9. Does the nursing care plan include nursing diagnoses or identifled problems?

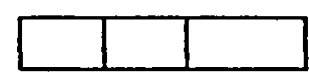

10. Does the nursing care plan include short term goals?

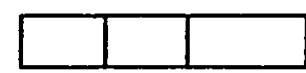

11. Does the nursing care plan include long term goals?

12. Does the nursing care plan identify assessments to be completed on visits?

13. Does the nursing care plan describe a teaching plan?

14. Does the nursing care plan describe nursing Interventions? 


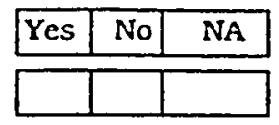

15. If a standardized nursing care plan is used. is it individualized to the particular patient?

III DOCUMENTATTON OF NURSING CARE

\begin{tabular}{|l|l|l|}
\hline Yes & No & NA \\
\hline
\end{tabular}
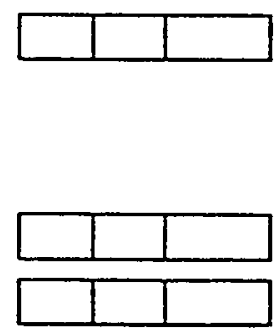

B.
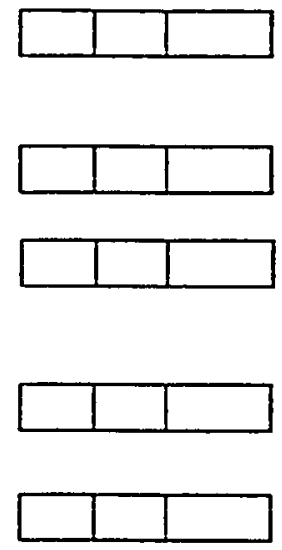

C. Intervention.

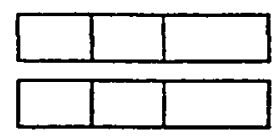

Assessment.
16. Documentation is present at least one time in the nurses notes that assess each diabetes mellitus nursing behavioral deficit/problem identined on the dutribasa cllnical findings of the HICFA form? le: knowledge defictt, hyperglycernla. visual deficit.

17. Are blood glucose levels documented on each visit?

18. As patient progresses toward discharge. do nurses notes assess patlent's/caregiver's abllity for self care?

B. Pattent Teaching.

19. Instruction in blood glucose montoring technique is glven untll patient/careglver can perform safely is documented.

20. Instruction in diet is given untll patient/caregiver can demonsthite understancling is documented.

21. Instruction in diabetes medication administration is documented until patient/caregiver can perform safely is documented.

22. Instruction on signs and symptoms of hypoglycemia is documented.

23. Instruction on treatment of hypoglyccmia is documented.

24. Was blood glucose meter and/or supplues ordered?

25. Were Interdisciplinary referrals ordered, 1.e. social . work, elderly services, occupational therapy? 


\begin{tabular}{|l|l|l|}
\hline Yes & No & NA \\
\hline
\end{tabular}
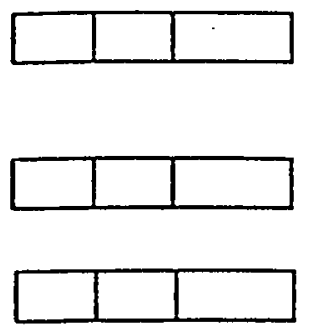

D. Evaluatlon.
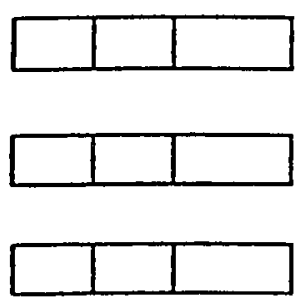
29. Do nurses notes show evidence of evaluation/revision of nursing care plan?

30. Is progress/lack of progress toward self/family management of diabetes mellitus documented?

31. Is progress/lack of progress toward stability of blood sugars documented?

IV. DISCHARGE.VISIT: Review last visit nurses notes and/or discharge summary - form.

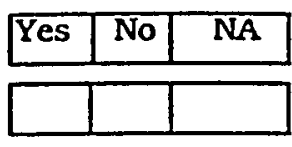

32. Is there documentation of any of the following: patlent/careglver skill and/or knowledge of care. safety precautions, or support systems.

33. Is a blood sugar documented?

By David L. Cook, RN, CDE

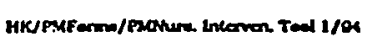

Revised by Val Isaacson, RN, 1995 
Appendix D

Patient.Characteristics Questionnairc (PIQ) 


\section{PATIENT CHARACTERISTICS QUESTIONNAIRE}

Age: Sex: ID Number:

Marital Status: (circle) married, single, widow, divorced

Race: (circle) Caucasian, Black, Hispanic, Asian

Is English Patients Primary Language? yes___no___ Caregiver? yes__no__

Who is Caregiver: (circle) self, spouse, other family member (who) non-family member (who)

Admitted to home health agency from: (circle) self care, family caregiver, hospital, SNF, RCH, other (where)

Strock Level of Care (I, II, or III) at: Start of care Discharge

Type of Diabetes: (circle) Type I (IDDM), Type II (NIDDM), not identified

Diabetes Onset Date: prior date of hospitalization for diabetes

Current Treatment Plan: (circle all that apply) diet, exercise, oral agent, insulin

Blood Pressure: admit , discharge

Blood glucose - random/FBG: admit , random/FBG: discharge

Diabetes Mellitus Complications (place check by all categories that are documented)

A. Neuropathy (neurogenic bladder, gastroparesis, cardiomyopathy, peripheral)

B. Renal (renal insufficiency, renal failure, dialysis)

C. Retinopathy

D. Lower Extremity ulcers

E. Amputation (non-traumatic)

F. Macrovascular: (peripheral vascular disease, coronary artery disease, cerebral vascular disease/accident

Used with permission of David L. Cook, 1994

Modified by Valerie Isaacson, 1995 
Appendix $\mathrm{E}$

Human Subjects Approval 
Otfice of the Academic Vice President • Assoclate Academic Vice President • Graduate Sludles and Research

One Washington Square • San José, California 95192-0025 • 4C8/924-2480

TO: Valerie Isaacson

2298 Elkhorn Court

San Jose, CA 95125

FROM :

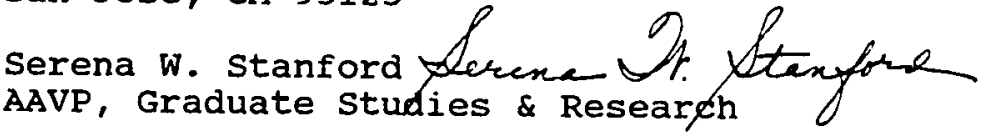

DATE :

May 9, 1995

The Human Subjects-Institutional Review Board has approved your request to use human subjects in the study entitled:

"Comparing Nurses" Knowledge of Diabetes and Diabetic

Patient Outcomes at Two Home Health Agencies"

This approval is contingent upon the subjects participating in your research project being appropriately protected from risk. This includes the protection of the anonymity of the subjects' identity when they participate in your research project, and with regard to any and all data that may be collected from the subjects. The Board's approval includes continued monitoring of your research by the Board to assure that the subjects are being adequately and properly protected from such risks. If at any time a subject becomes injured or complains of injury, you must notify serena Stanford, Ph.D.; immediately. Injury includes but is not limited to bodily harm, psychological trauma and release of potentially damaging personal information.

Please also be advised that each subject needs to be fully informed and aware that their participation in your research project is voluntary, and that he or she may withdraw from the project at any time. Further, a subject's participation, refusal to participate, or withdrawal will not affect any services the subject is receiving or will receive at the institution in which the research is being
conducted.

If you have any questions, please contact me at (408) 924-2480. 
56

Nov. 10, 1994

Dear Valerie,

I am sending you a copy of the Diabetes Basic Knowledge Test. I have not submitted my manuscript for publication, but plan to in the near future. You will understand how burnt out one can feel after graduating!

I am also sending you a copy of the easy to understand abstract I gave to the two institutions that participated in my study. I have included certain pages from my thesis that I think may help you with the tool.

Please let me know of any other way I may help you. You may also reach me by phone if you wish:

Work: (509)455-3207

Home: (509)325-8864

I wish you luck in obtaining your Master's Degree. It is 2 well earned degree!

Sincerely your,

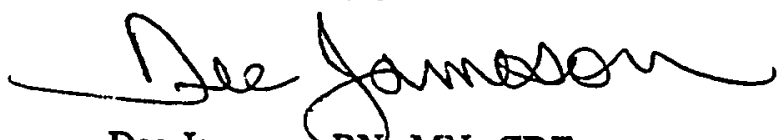

Dee Jameson, RA, MN, CDE

Sacred Heart Medical Center

P.O. Box 2555

Spokane, WA 99220-2555

PS.

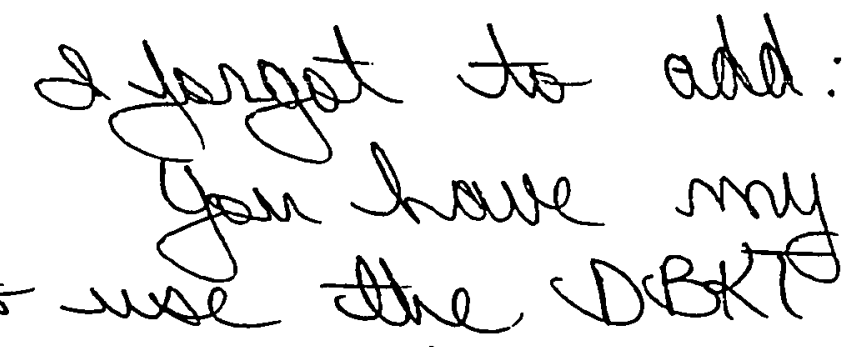

thesis

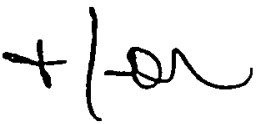

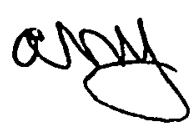

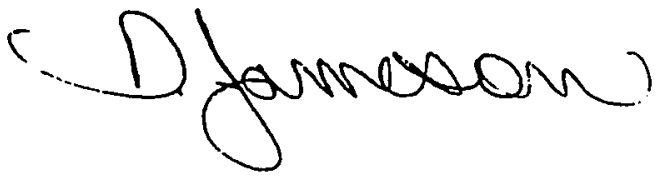

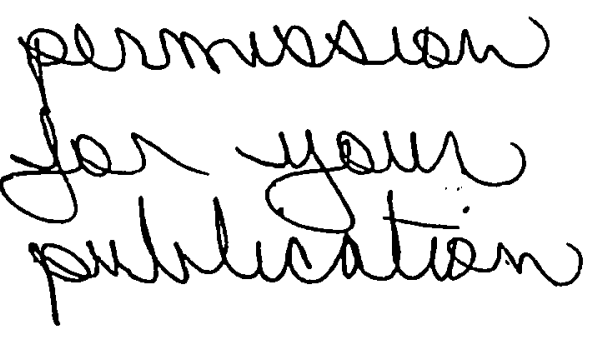




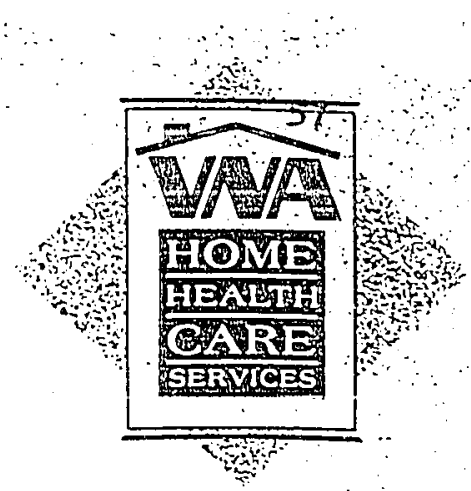

MAIL: P.O. BOX.3989

SPOKANE, WA 99220-3989:

PHONE 509・534・4300

FAX $509 \cdot 536 \cdot 6464$

August 2, 1994

STREET: E. 3901 MAIN

SPOKANE, WA $99202-4736$

Val Isaacson has permission to use the following research tools: Nurse

Information questionnaire, Patient Characteristic Questionnaire and Nursing Care Intervention Tool. I would appreciate a copy of any changes you may make on these tools and any further validation you may do.

Sincerely.

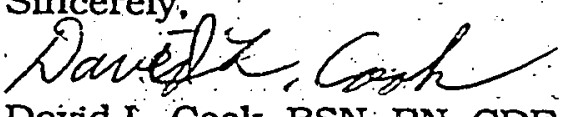

David L. Cook, BSN, RN. CDE 